\title{
Work in Progress: Vertical Integration of Engineering Design in an Under- graduate BME Curriculum
}

\section{Dr. Steven Higbee, Indiana University Purdue University, Indianapolis}

Steve is a Clinical Assistant Professor of Biomedical Engineering at Indiana University-Purdue University Indianapolis. He received his PhD in Bioengineering from Rice University (Houston, TX) in 2013, after earning his BS and MS degrees from Purdue University (West Lafayette, IN). His current position focuses on teaching, advising, and promotion of undergraduate research.

\section{Dr. Sharon Miller, Indiana University Purdue University, Indianapolis}

Dr. Miller is the Undergraduate Program Director and Clinical Associate Professor of Biomedical Engineering at Indiana University-Purdue University Indianapolis (IUPUI). After earning her BS in Materials Science and Engineering from Purdue University (West Lafayette), she earned her MS and PhD degrees at the University of Michigan (Ann Arbor). Her current roles include teaching, assisting in program assessment, student advising, and helping oversee undergraduate curriculum development and enhancement. 


\title{
Work in Progress: Vertical Integration of Engineering Design in an Undergraduate BME Curriculum
}

\begin{abstract}
Relevant and robust biomedical engineering programs integrate challenging, hands-on engineering design projects that require student teams to develop and deliver functional prototypes in response to biomedical design problems. The inclusion of such projects throughout Biomedical Engineering (BME) curricula not only brings active learning to the classroom but helps students improve as team members, decision makers, and problem solvers. This work highlights how sophomore and junior level engineering design projects can increase students' fundamental engineering design knowledge and self-reported confidence in approaching design projects. By steadily increasing the complexity of engineering design experiences throughout the BME undergraduate curriculum, our continued work studies whether intentional, vertical alignment of engineering experiences ultimately better prepares BME undergraduates for their senior design capstone projects and their professional pursuits.
\end{abstract}

\section{Introduction}

Inductive teaching methods have encouraged higher levels of student cognition [1]-[2], improved student teamwork and communication [3], and allowed increased student confidence during engineering design prototyping [4]. Paired with a resurgence of hands-on learning in the engineering community [5], inductive teaching methods allow instructors to incorporate real problems that require physical prototype solutions. Our work aims to incorporate one specific inductive teaching method, project based learning (PBL), into sophomore and junior level Biomedical Engineering (BME) laboratory courses. When designed well, PBL experiences can allow students to achieve attainable cognitive growth [6]-[8] that can be applied when design challenges become more difficult.

The literature is replete with examples of instructors who have adapted their lecture and laboratory courses in ways that present students with more open-ended or design-oriented challenges. These examples vary widely in their levels of student expectations; some are theoretical design problems done entirely with pen and paper, while others are highly rigorous assignments that lead students through decision making, modeling/analysis, and prototype development [9]-[11]. Few of the projects found in the literature, however, compel students to systemically understand and utilize the engineering design process in their design work.

Engaging students in the BME design process is paramount as the design of medical devices is subject to increased scrutiny and control due to the highly regulated nature of these products. To help our students apply the engineering design process to medical device development, a common BME Design Module was developed that adapts the FDA waterfall diagram to capture the BME design process in greater detail. In each course, common biomedical devices are discussed as examples to help guide students through the BME design process. Sophomore and junior level design projects, each with defined needs and requirements, challenged student teams to engage in an iterative decision-making process when developing and communicating a solution. By intentionally emphasizing different portions of the design process in the sophomore 
and junior projects, a stepwise approach is being used to build student design knowledge and confidence.

\section{Methods and Assessment Measures}

Common BME Design Module: Curricular materials that highlight the use of the engineering design process in medical device development were developed and presented to students. Each module emphasizes a different part of the BME design process. Specifically, a 15-minute introduction of medical device development was followed by a relevant, accessible discussion involving an already approved device. Each design project was then introduced and student teams worked on the projects in parallel with their laboratory coursework. Students maintained access to both the Design Module and project files via the course learning management system.

Design Project Development: To date, two project-based design assignments that balance students' prior knowledge with realistic prototype expectations have been introduced in our curriculum (Table I). Two additional project-based assignments will be assigned in spring, resulting in a coordinated sequence of projects that students experience every semester in the curriculum. In each project, teams of 3-5 students were assigned by instructors. Design projects were integrated into laboratory courses with design deliverables replacing previous laboratory assignments. Specifically, two of the four design projects were inspired by existing laboratory experiments but altered to be more open-ended as to promote engineering design approaches. For each design project, students were assigned two deliverables throughout the semester to provide an opportunity for instructor feedback prior to submission of the final design report.

Table I: Sophomore (200-level) and Junior (300-level) BME Design Projects

\begin{tabular}{|c|c|c|}
\hline . & 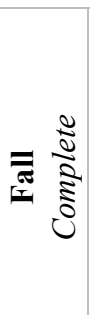 & $\begin{array}{l}\text { Introductory Biomechanics } \\
\text { Fracture Fixation Plate: Design and } \\
\text { model mechanical design for fracture } \\
\text { fixation } \\
\text { Emphasis: Iterative Design, Modeling } \\
\text { and Analysis }\end{array}$ \\
\hline $\begin{array}{l}0 \\
\frac{0}{0} \\
\frac{1}{8} \\
0 \\
0\end{array}$ & 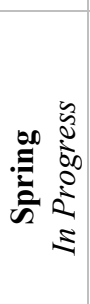 & $\begin{array}{l}\text { Introductory Biomeasurements } \\
\text { Electromyography Device: Use } \\
\text { electrical signals from muscles to control } \\
\text { a motor } \\
\text { Emphasis: Defining User Needs, } \\
\text { Software Design }\end{array}$ \\
\hline
\end{tabular}

\begin{tabular}{|c|c|c|}
\hline $\begin{array}{l}\frac{\infty}{0} \\
.0 \\
0\end{array}$ & 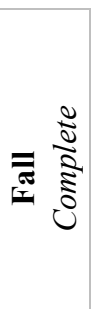 & $\begin{array}{l}\text { Implantable Materials } \\
\text { Spectrophotometer [9]: Measure } \\
\text { molecular concentration for medical } \\
\text { diagnostics } \\
\text { Emphasis: Refining and Optimizing, } \\
\text { Verification and Validation }\end{array}$ \\
\hline$\frac{\bar{d}}{\frac{0}{0}}$ & 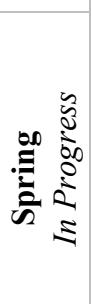 & $\begin{array}{l}\text { Cell and Tissue Behavior and } \\
\text { Properties } \\
\text { Drug Dosing Device: Control pumps to } \\
\text { achieve desired concentration profiles } \\
\text { Emphasis: Hardware/Software } \\
\text { Interfacing, Design Verification }\end{array}$ \\
\hline
\end{tabular}

In the sophomore year, students in an introductory biomechanics course were assigned a fracture fixation design project that emphasizes the role of engineering analysis in the design process. Student teams were tasked with making iterative improvements to a rudimentary fracture fixation device used computer modeling tools (computer-aided design and finite element analysis) to analyze design changes. Students fabricated prototypes and performed mechanical testing to assess model accuracy. In the junior year, students in an implantable materials course were assigned a spectrophotometer design project, which emphasized verification and validation 
testing in the design process. Teams designed, built, and verified accurate absorbance readings for their spectrophotometer designs. Additionally, students interfaced their spectrophotometers via LabVIEW and validated their devices by using them to perform a team-chosen application.

The overarching goal of vertically integrating design in a BME curriculum is to prepare undergraduates to approach complex engineering problems. To accomplish this, integrated projects expose students to various biomedical topics, engage students repeatedly in the design process, and increase in complexity from 200- to 300-level. Projects at the 200-level focus on defining user needs and iterative design, whereas the 300-level projects emphasize hardwaresoftware integration and prototype verification testing. As capturing changes in senior design performance requires longitudinal study, students' fundamental knowledge and confidence are first being assessed.

Mixed Methods Evaluation: A mixed methods approach is being used to gather data via quizzes, surveys, and project reports to evaluate two student learning outcomes. Existing, adapted, and new assessment tools were used in combination to evaluate the learning outcomes. Two-sample Student's t-tests were used to determine statistical significance for quantitative comparisons.

Outcome 1: Students will demonstrate knowledge of the BME design process. A pre-/post-test (8 questions worth 10 points total) assessed if students could identify definitions of design control and how these concepts apply towards medical device design. Student project reports were scored using an instructor rubric influenced by AAC\&U VALUE Rubrics [12], Informed Design Teaching and Learning Matrix [13], and the Transferrable Integrated Design Engineering Education (TIDEE) [14], [15] tools. Students also self-reported design mastery via a survey.

Outcome 2: Students will demonstrate confidence when approaching a design problem or project. Students' self-reflections of design confidence before and after each project were collected. Students were also asked to rate how worthwhile and how enjoyable they found each project using a reflection grid [16].

\section{Results and Discussion}

Demonstrating Knowledge of Engineering Design Process: Students engaged in each project demonstrated knowledge gains of the BME design process (Table II). Specifically, both projects helped students identify components of the FDA waterfall diagram $(p<0.005)$ and apply them appropriately. Students in the 200-level course made gains in identifying design specifications ( $\mathrm{p}$ $=0.028)$, whereas students in the 300-level course showed increased knowledge of design requirements $(\mathrm{p}=0.014)$.

Table II: Pre-/Post-Test Means for 200-level and 300-level Design Projects

\begin{tabular}{r|cc} 
& 200-level $(n=41)$ & 300-level $(n=39)$ \\
\hline Pre-test & $3.53 \pm 1.72$ & $3.92 \pm 2.07$ \\
Post-test & $4.27 \pm 1.85$ & $5.83 \pm 1.86$
\end{tabular}


Project reports were analyzed to help identify student team design behaviors. Instructor scores indicated that student teams working on the fracture fixation project excelled at framing the design problem, generating design alternatives, and iterating. Troubleshooting and conducting experiments were areas to improve for these teams. The spectrophotometer project illustrated different areas of strength and weakness for the 300-level student teams. Instructor scores identified communication and conducting experiments as areas of strength, whereas generating ideas was an area to improve for these students.

At both levels, troubleshooting - focusing attention on problematic areas when engaged in design [13] - was identified by instructor rubric scores as an area to improve. Interestingly, students ranked their troubleshooting skills higher than most other design behaviors. This warrants further discussion around the meaning of troubleshooting and approaches informed designers use. As more data are collected, the investigators will monitor where in the curriculum students are learning specific design behaviors. This will better inform BME instructors where students are developing within the curriculum as a whole.

Integrating Prior Coursework into Design: Student reflections ( $\mathrm{n}=23$ for $200-$ level, $\mathrm{n}=34$ for 300-level) identified fundamental knowledge used in accomplishing their designs in addition to where they learned this information. Students engaged with the fracture fixation design project in the 200-level course most often referenced Introductory Biomechanics (48\%) or a freshman engineering course requirement (57\%) as useful in the design process. Skills or tools identified included CAD software or equivalent (35\%), MATLAB (17\%), and the design process (22\%). Students that completed the spectrophotometer design project referenced one particular BME course, Introductory Biomeasurements, as the most (71\%) influential preparation for the project. Specific skills noted were LabVIEW (38\%) and circuit design (50\%). No students in the 300level course explicitly stated that the fundamental knowledge of the design process was applied.

The instructor rubric used to analyze student team reports in both courses included a technical approach section, which mainly gauged the student teams' abilities to apply prior knowledge correctly into the design. All student teams in the 200 -level course and $50 \%$ of the student teams in the 300-level course appropriately identified prior knowledge and applied concepts towards design. As it is difficult to directly compare the two projects, it is clear that the junior-level project should be revisited to include additional technical resources or direct instruction.

Demonstrating BME Design Confidence: Survey questions asked students to report their perceived self-confidence on a Likert Scale (1-not very confident, 3-neutral, 5-very confident), before and after each project, in four categories: Design Process/Approach, Hardware/Physical Parts, Software/Interfacing with Hardware, and Communication. Students reported increased confidence in all four categories (Table III, $\mathrm{p}<0.05$ for all before/after mean comparisons).

Students that participated in the 200-level course project showed larger perceived confidence gains in regards to Hardware and Software, whereas students in the 300-level course relayed higher confidence gains in the Design Process/Approach. Interestingly, both sets of students showed, on average, the highest confidence in Communicating Results. 
Table III: Student, Self-Reported Confidence Before and After Project Completion in Both 200-level and 300-level Courses

\begin{tabular}{r|ccc} 
200-level Course (n=35) & $\begin{array}{c}\text { Confidence } \\
\text { Before } \text { Project }\end{array}$ & $\begin{array}{c}\text { Confidence } \\
\text { After Project }\end{array}$ & $\begin{array}{c}\text { Mean } \\
\text { Improvement }\end{array}$ \\
\hline Design Process/Approach & $2.69 \pm 1.12$ & $3.63 \pm 0.90$ & 0.94 \\
Hardware/Physical Parts & $2.29 \pm 1.08$ & $3.69 \pm 1.04$ & 1.40 \\
Software/Interfacing with Hardware & $2.06 \pm 1.01$ & $3.40 \pm 1.13$ & 1.34 \\
Communicating Results & $3.60 \pm 1.02$ & $4.14 \pm 0.72$ & 0.54 \\
& & & \\
300-level Course $(\mathbf{n}=\mathbf{2 8})$ & $\begin{array}{c}\text { Confidence } \\
\text { Before } \text { Project }\end{array}$ & $\begin{array}{c}\text { Confidence } \\
\text { After Project }\end{array}$ & $\begin{array}{c}\text { Mean } \\
\text { Improvement }\end{array}$ \\
\hline Design Process/Approach & $2.89 \pm 0.98$ & $3.96 \pm 0.68$ & 1.07 \\
Hardware/Physical Parts & $3.04 \pm 0.82$ & $4.00 \pm 0.65$ & 0.96 \\
Software/Interfacing with Hardware & $2.07 \pm 0.92$ & $2.93 \pm 0.88$ & 0.86 \\
Communicating Results & $3.79 \pm 0.94$ & $4.21 \pm 0.56$ & 0.43
\end{tabular}

Students were asked to rate how worthwhile and how enjoyable they found each project. Heat maps of responses (Figure 1) indicate that $68 \%$ and $74 \%$ of students in the 200 - and 300 -level course, respectively, found the design projects worthwhile to some degree. In fact, $55 \%$ of $200-$ level students and $46 \%$ of 300 -level students found the projects both worthwhile and enjoyable. For some students the design project was the first time that they were challenged to work on a project with no direct answer or lab guide, so it is not surprising that many did not enjoy the projects. However, these data indicate that better delivery of the projects and better management of teams could improve the overall student outcomes and students' perceived enjoyment.
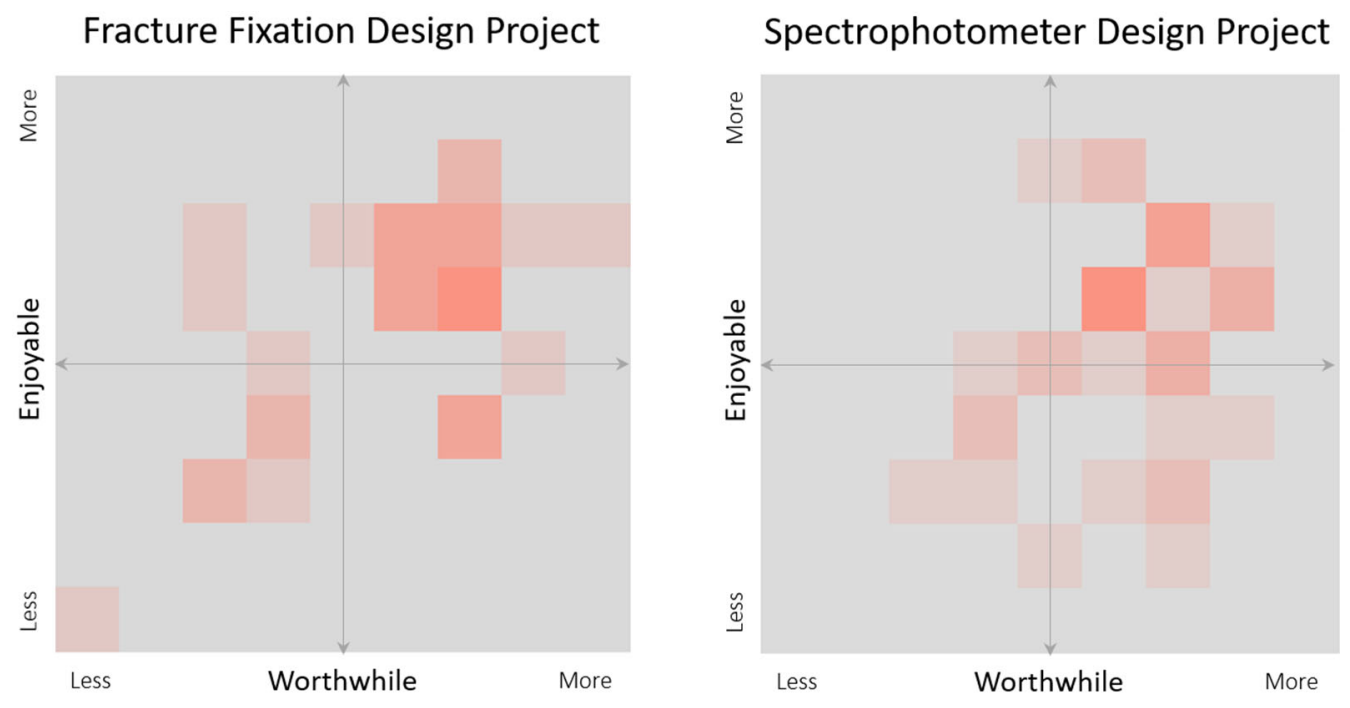

Figure 1: Heat map showing students' perceptions of the design activities with respect to being worthwhile or enjoyable ( $\mathrm{n}=31$ for 200 -level course, $n=35$ for 300 -level course). Grey squares indicate zero responses; increasing red intensity indicates increasing number of responses. 
Biomedical Engineering (BME) programs often provide strong laboratory and project experiences aimed at preparing students for senior capstone. These culminating engineering design experiences require students to be adept at using an iterative design process to generate and represent design solutions. Providing students with more opportunities to apply the BME design process will continually engage students, build design confidence, and ultimately yield improved capstone designs. Our ongoing work implements two more design projects in 200- and 300-level courses in the spring semester of our program. All data will be analyzed collectively to assess achievement of student learning outcomes. In the end, our goal is to have all of our BME students experience four BME design projects prior to senior capstone. Bringing in active learning experiences, like project based learning, is already showing increased confidence when students reflect on the projects. Our preliminary data shown here are encouraging, but incomplete. Because all of the design projects involve student teams, a future direction will be to assess teamwork to investigate relationships between team dynamics and student perception of each design project. The long term goal of this work is to monitor senior capstone project quality in tandem with students' self-confidence in approaching BME Design.

\section{Acknowledgments}

The authors would like to thank the Center for Teaching and Learning for their Curriculum Enhancement Grant (CEG) support. We would also like to thank the Chair of the Biomedical Engineering Department for matching financial support.

\section{References}

[1] M.J. Prince and R.M. Felder, "Inductive Teaching and Learning methods: Definitions, Comparisons, and Research Bases," Journal of Engineering Education, pp. 123-138, Apr. 2006.

[2] J.C. Perrenet, P.A.J. Bouhuijs and J.G.M.M. Smits, “The Suitability of Problem-based Learning for Engineering Education: theory and practice," Teaching in Higher Education, vol 5(3), pp. 345-358, 2000.

[3] J.E. Mills and D.F. Treagust, "Engineering Education-Is Problem-Based or Project-Based Learning the Answer?" Australasian Journal of Engineering Education, pp. 2-16, 2002.

[4] A. Aditomo, P. Goodyear, A. Bliuc, and R.A. Ellis, "Inquiry-based learning in higher education: principal forms, educational objectives, and disciplinary variations", Studies in Higher Education, vol 38:9, pp. 1239-1258, 2013. DOI: 10.1080/03075079.2011.616584

[5] J.E. Froyd, P.C. Wankat, and K.A. Smith, "Five Major Shifts in 100 Years of Engineering Education," Proceedings of the IEEE, vol 100, pp. 1344-1360, May 2012.

[6] D. Kokotsaki, V. Menzies, and A. Wiggins, "Project-based learning: A review of the literature," Improving Schools, vol 19(3), pp. 267-277, 2016.

[7] C.L. Dym, A.M. Agogino, O. Eris, D.D. Frey, and L.J. Leifer, "Engineering Design Thinking, Teaching, and Learning”, Journal of Engineering Education, pp. 103-120, 2005. 
[8] I. De Los Rios-Carmenado, F. Rodriguez Lopez, and C. Perez Garcia, "Promoting Professional Project Management Skills in Engineering Higher Education: Project-Based Learning (PBL) Strategy," International Journal of Engineering Education, vol 31(1B), pp. 184198, 2015.

[9] K. Bougot-Robin, J. Paget, S.C. Atkins, and J.B. Edel, "Optimization and Design of an Absorbance Spectrometer Controlled Using a Raspberry Pi To Improve Analytical Skills," Journal of Chemical Education, pp. 1232-1240, Mar. 2016.

[10] T.D. Giorgio and S.P. Brophy, "Challenge-Based Learning in Biomedical Engineering: A Legacy Cycle for Biotechnology," Proceedings of the American Society for Engineering Education Annual Conference \& Exposition, 2001.

[11] J. Yao and S. Warren, "Stimulating Student Learning with a Novel 'In-House' Pulse Oximeter Design," Proceedings of the American Society for Engineering Education Annual Conference \& Exposition, 2005.

[12] T. Rhodes, Assessing outcomes and improving achievement: Tips and tools for using rubrics. Washington, DC: Association of American Colleges and Universities, 2010.

[13] D.P. Crismond and R.S. Adams, "The Informed Design Teaching and Learning Matrix," Journal of Engineering Education, Vol 101, no 4, pp. 738-797, Oct 2012.

[14] D.E. Calkins, D.C. Davis, R.W. Drain, M.S. Trevisan, and K.L. Gentili, "TIDEE: the first year of a design engineering educational partnership for Washington State," Proceedings of Frontiers in Education Conference 26th Annual Conference, Salt Lake City, UT, pp. 1374-1378 vol.3 1996.

[15] D. Davis, M. Trevisan, L. McKenzie, S. Beyerlein, P. Daniels, T. Rutar, P. Thompson, and K. Gentili, "Practices for Quality Implementation of the TIDEE 'Design Team Readiness Assessment", Proceedings of the American Society for Engineering Education Annual Conference \& Exposition, 2002.

[16] Reflection Workshop Workbook, Consortium to Promote Reflection in Engineering Education, Sept. 2017. 